the memoir of Sir J. Hall (Trans. R. S. E., vol. vii. 1813), and to that of the Petit Bornand in Savoy. (Favre, Recherches, pl. x.) ; at $b$ is a valley open at one of its ends and almost closed at the other; at $e$ is a vault almost straight, the prolongation of which is very level; at $g, h$, and $l$ are vaults twisted and a little broken, while at $i$ is a broken fold, the curves of which are almost vertical. All these accidents of the ground recall those which have been so often observed in the Jura, the Alps, and the Appalachians.

Fig. 2 represents a band of clay whose thickness was about $40 \mathrm{~mm}$. before compression, and 65 after. We remark contortions similar to those of the preceding figure, among others a vault $a$, very exactly formed. At distances are seen vertical slices, on which the pressure appears to have acted in a particularly energetic fashion, and which may be called "zones de refoulement;" the strata are there broken in an exceptional manner, often separated from each other. One of these vaults is replaced by a single fault on the opposite side of the band of clay.

Before compression, in the band of clay in Fig. 3, were seen the two divisions which are seen there now-that in the right was $33 \mathrm{~cm}$. long, and $25 \mathrm{~mm}$. thick at $a_{\text {s }}$ and 35 at $b$; the left division was $25 \mathrm{~cm}$. long, and $65 \mathrm{~mm}$. thick. A gentle slope united the part $c$ to the part $b$. After compression, the mean height of $a b$ was 45 , and that of $c$ $75 \mathrm{~mm}$. All the layers were spread horizontally.

In this experiment I have sought to imitate the effect of crushing at the limit of a mountain and a plain. The height of the mountain $c$ has been notably increased, the five or six upper layers have advanced on the side of the plain; they encroach on it. The plain has, however, offered a resistance sufficiently great to cause the strata of the mountain to be strongly inflected at the bottom. From this struggle between the plain and the mountain, there resulted a cushion, $d$, which is the first hill at the foot of the height. It also resulted that the strata of the plain assumed an appearance of depression at contact with the mountain in , consequence of the vault which is formed at $b$; they plunge underneath the mountain. This resembles what is often seen in the Alps at the junction of the first calcareous chain and the hills of "mollasse;" in fact, the strata of the latter rock seem to plunge under those of the neighbouring heights. In consequence of the pressure, there are formed several ranges of hills in the plain between $b$ and $a$.

"In Fig. 4 the band of clay had, before compression, a thickness of $45 \mathrm{~mm}$.; after that the culminating point was more than ro $\mathrm{cm}$. I have here sought to represent what must happen when terrestrial pressure is exerted on horizontal strata still moist, deposited at the bottom of a sea where are two mountains already solidified. For this purpose I placed in the caoutchouc and under the clay two bare cylinders of wood, $a$ and $b$, of labout $35 \mathrm{~mm}$. cadius, at $20 \mathrm{~cm}$. from the ends of the band of clay, and at the same distance from each other. Before compression, the surface of the clay and the strata were completely horizontal. Pressure gave rise at the top of the half-cylinder, $a$, to a valley, $c$, formed by a twisting of the beds to the right, and by a little mountain, $d$, to the left. But I do not believe that it has ever been thought to assign to a valley an origin of this nature.

"On the other semi-cylinder, $b$, is produced an enormous elevation which has carried the ground to $e$, with such a rapture that the left lip, $f, g$, has suffered a complete reversal by turning, as on a hinge, around the horizontal line which passes by the point $h$. It follows that the four upper strata of clay designated by the figures $1,2,3,4$, being in a normal position before compression, are, after that, so arranged as to show the succession represented by the following arrangement of figures:- $-I, 2,3,4,4,3$, $2,1,1,2,3,4$, making the section of this formation by 2 line drawn from $x$ to $z$. If the left lip should disappear we should then have between the points $x$ and $z$ the section $1,2,3,4,5,1,2,3,4,5$. Sections analogous to these, presenting inversions in the order of strata, are known to geologists.

"The forms assumed by the clay depend on several circumstances which it is difficult to describe; such as the strength and the rate of compression, the thickness and the greater or less plasticity of the clav, \&c. Why have accidents of the upper surface of the clay, which are intimately connected with those of the interior of the mass, so small an extension that they are not even similar in the two sides of a band of clay? This small continuity is owing to causes which we can neither foresee nor appreciate. Is it not the same in nature? Why is the chain of the Alps not a true chain, but a succession of masses often oblique with respect to each other? Why, in the Jura, do we see chains which have for their prolongation plains and valleys? It is always the case that the forms and structures obtained in these experiments have an incredible resemblance to those which are found on the surface of the globe. But it must be admitted that many of the latter have not been reproduced by these artificial crushings.

"It appears probable that, by pressures more powerful and more variedly employed, we might obtain again very different structures. But I have not thought it necessary to multiply these experiments, thinking that the varied forms which have resulted show sufficiently the effects of crushing."

\section{GEORGE HENRY LEWES}

THIS is a name which has been long before the reading public of England, and the announcement of Mr. Lewes's death, on Saturday last, at the age of sixty-one years, will be received by very many with genuine regret.6 This will be especially the case with those who have reached or passed middle life, for latterly Mr. Lewes's name has come little before the public, and what work he has done appeals to a comparatively small circle. Of Mr. Lewes's many-sidedness every one knows; he commenced his career as a novelist, and ended as a physiological psychologist-perhaps in some respects no very great leap, fter all; indeed the two functions may be said to be combined in that greatest of philosophical novelists, if not of novelists absolutely, "George Eliot," Mr. Lewes's widow. Science owes a good deal to Mr. Lewes; for, though he made little or no pretension to be an original investigator in physical science, he did very much by his writings to give the general public an idea of what real science is, and to help forward the good work of carrying it into every-day life. His "Physiology of Common Life" had a long and deserved popularity, and even yet, we believe, is often "asked for" at libraries and book-shops. His "Biographical History of Philosophy" is thoroughly readable and full of information, which is more than can be said of philosophical works generally. Of his "Life of Goethe," one of the very few masterly biographies, we leave it to others to speak, though he did much there to bring out the real importance of Goethe's botanical and other scientific researches. Of his latest work, "Problems of Life and Mind," we spoke at length on the appearance of the volumes that have been published; in these volumes and in one or two letters and articles contributed to our pages, Mr. Lewes was perhaps at his best as an investigator in a department of science with which we are cautious of interfering, but which has a strange fascination for many thinkers. Altogether Mr. Lewes filled an important and many-sided place in the intellectual life of this country during his long career. It is easy to say that a man of his unusual keenness of mind might have achieved permanent greatness by concentrating his great store of energy in one 
particular direction; but then he would not have been the innately versatile George Henry Lewes. His influence has been spread over a wide field, and has been largely beneficial to progress and enlightenment; he never aimed, we believe, at piling up an enduring monument to himself.

\section{(n)}

\section{NOTES}

Mr. E. J. Stone, F.R.S., Astronomer-Royal at the Cape of Good Hope, has been appointed to the Radcliffe Observatory, Oxford, in place of the late Rev. R. Main.

Mr. William Spottiswoode, having been elected President of the Royal Society on Saturday last, has resigned the office of Secretary to the Royal Institution. At the meeting, on Monday last, it was proposed that the Members of the Royal Institution subscribe to present a bust of Mr. Spottiswoode to the Institution as a recognition of his valuable services as Treasurer and Secretary successively.

WE have already referred to the new Parkes Museum of Hygiene, at University College, London, and we now earnestly draw our readers' attention to the appeal made by the Executive Committee for subscriptions towards an endowment, which is absolutely necessary for the efficiency of the institution, in diffusing the much needed knowledge of sanitary appliances and their uses. Although quite in its infancy, the Parkes Museum contains objects relating to life-protection, dietetics, clothing, furnishing, engineering, and architecture--in fact, every branch of hygiene. The library already consists of between 300 and 400 volumes, exclusive of pamphlets. "It cannot be too widely known," the Executive Committee state, "that it is intended to extend the benefits of the Museum to all classes, so that not only professional men, but owners of property, employers of labour, artisans, and others, both men and women, may be able to study at their leisure the subjects in which they are most interested." The Executive Committee, therefore, confidently appeal for pecuniary support to all those who, while being interested in tcchnical education and sanitary science, have the inclination and the means to give such assistance. The Committee will not only be glad to receive subscriptions of money, but also books and pamphlets in any language, statistical tables, maps, plans, and other drawings, models, apparatus, or specimens illustrating any branch of hygiene. Subscriptions may be paid to the Treasurer, Mr. Berkeley Hill, 55, Wimpole Street, W. All communications relating to the presentation of articles to the Museum should be addressed to the Curator, Mr. Mark H. Judge, Parkes Museum, University College, Gower Street, W.C.

The Daily New's' New York correspondent telegraphs that Mr. Edison announces that he has perfected a machine for measuring the current used in the electric light. It consists of an apparatus placed in every house lighted by electricity, which registers the quantity of electricity consumed, and uses for the purpose the one-thousandth part of the quantity con. sumed in the building. Mr. Edison declares that his invention of the light, including the arrangement for counteracting loss in subdivision, is now completed. His experiments at present are directed to reducing the cost. He has, he says, already brought this decidedly below the cost of gas, and as soon as the minimum is.reached, will make the results public. The New York World contains the following interesting details of Mr. Edison's doings :--"Dozens of workmen and machinists are hard at work at Menlo Park on the new buildings, the workshop being now almost ready for the roof. Mr. Edison said to a reporter for the World, 'I don't know when I am going to stop making improvements on the electric light. I've just got another one that I found by accident. I was experimenting with one of my burners when I dropped a screw-driver on to it. Instantly the light was almost doubled and continued to burn with the increased power. I examined the burner and found it had been knocked out of shape. I restored it to its original form, and the light was decreased. Now, I make all my burners in the form accidentally given to that one by the screw-driver. The result is that I can produce the amount of light given out by the first burner with little more than half the power. It is almost impossible to $\mathrm{cal}$ culate with certainty the resources of my light, but I have engaged a mathematician to work out the problem from my data.' On the whole, Mr. Erlison states he is confident of success, however much any one may be puzzled by his methods or claims."

THE Corporation of Liverpool have given notice that they intend to apply in the ensuing Session for an Act authorising the lighting of the public streets, places, and buildings within the borough by means of the electric light, "or otherwise than by means of gas." The Corporations of Warrington, Derby, South Shields, Leicester, Blackburn, Over Darwen, and Stratford-upon-Avon, in conjunction, in the latter borough, with the Local Board of Health, ask for similar powers in the Bills which they intend to promote.

THE sixth part of the illustrated work of C. J. Maynard on the "Birds of Florida, and the Water and Game Birds of Eastern North America," has just been published, and contains three quarto plates, one of them representing sixty-six pecies of eggs.

Messrs. MaCmillan and Co. will shortly publish "Notes of a Naturalist on Board the Challenger," by Mr. H. N. Moseley, F.R.S., who was on the scientific staff of the expedition. The work will be illustrated.

THE zoological station of the Zoological Society of the Netherlands has published its third report. During the summer of $187^{8}$ the station was erected on the Island of Terschelling, and in the course of two months it was visited by ten zoologists. This year the investigation of the Zujder-Zee was the principal object kept in view, and for that purl ose some fourteen dredging excursions with the boat stationed in West-Terschelling for laying buoys were organised. The station underwent no small improvement, a nicely-organised aquarium-room being added to the main building. Here a small hot-air engine of about $\frac{1}{10}$-horse power (construction of D. W. van Rennes, Utrecht) drives an air-forcing pump; the compressed air gathered in a white-iron box is distributed through numerous aquarium-vessels by means of gum-elastic tubes and small glass-canules. By means of this arrangement even on hot days numerous animals were kept alive. The investigation of the Zuider-Zee not being brought to a close, the Island of Terschelling will probably next year see the station again erected in one of its picturesque valleys.

Ar last week's meeting of the Paris Academy M. Pasteur read a critical examination of the posthumous papers of Claude Bernard, in which statements were made opposed to the conclusions reached by $M$. Pasteur. He regards the manuscript of Bernard as a sterile attempt to substitute for well-established facts the deductions of an ephemeral system. "The errors, however," M. Pasteur says, "of those who in the sciences have accomplished a valiant career have only the philosophical interest which attaches to the knowledge of our human frailty."

THE following are the probable arrangements of the Royal Institution for the Friday Evening Meetings before Easter, I879:- January 17, Prof. Tyndall, "The Electric Light;" January 24, Prof. W. E. Ayrton, "The Mirror of Japan and its Magic Quality;" January 3r, Mr. H. Heathcote Statham 